\title{
GEOMETALURGIA APLICADA AO PROCESSO DE PELOTIZAÇÃO COM FOCO EM PRODUÇÃO E CONSUMO ENERGÉTICO*
}

\section{Resumo}

Marcos Meyer Machado ${ }^{1}$ Leandro Resinentti Zanon ${ }^{2}$

O presente trabalho compreende um estudo sobre os processos de moagem e tratamento térmico de pelotas no que tange as implicações microestruturais de minério de ferro no controle operacional e redução de consumos de energias térmica e elétrica de uma planta de pelotização. As características físicas, microestruturais e mineralógicas foram determinadas para os produtos de minério de ferro, para matriz de experimentos (misturas) e para as pelotas tratadas com auxílio de um microscópio óptico, um eletrônico e um EBSD. Os resultados permitiram confirmar a relação entre as composições morfológicas com a elevação de produção da moagem $(14,1 \%)$ e redução do consumo de energia elétrica $(12,0 \%)$. O controle do perfil térmico de endurecimento foi relacionado com as condições de sinterização (grau de maturação) das pelotas submetidas $e$ as fases microestruturais identificadas. Foi evidenciada relação inversa entre o teor de magnetita na mistura com o consumo de energia térmica. Os resultados de resistência à compressão também sugerem uma relação inversa com os teores de fayalita e magnetita não oxidada, porosidade e grau de maturação. Adicionalmente, os resultados proporcionaram ajustes industriais que confirmaram essa relação com a redução da energia térmica aplicada para produção (10,7\%).

Palavras chaves: processos de moagem; pelotas; fases microestruturais

\section{GEOMETALLURGY APPLIED TO PELLETIZING WITH FOCUS ON PRODUCTION AND ENERGY CONSUMPTION}

\section{Abstract}

This study is regarding of the iron ore microstructural characteristics implications in the operational process control and energy consumption of a pelletizing plant. All the samples characteristics were determined with the aid of an optical and electron microscope with EBSD. The results of the grinding tests have confirmed the relationship between the morphology of the iron ore blends with production rises $(14.1 \%)$ and energy consumption reduction (12.0\%). The control of the pot grate thermal profile was related with the sintering conditions (degree of maturation and porosity) of the pellets submitted and with the identification of microstructural phases. It was evidenced an inverse relation between the content of magnetite in the mixture with the consumption of thermal energy. The cold crushing strength results also suggest an inverse relationship with the contents of fayalite and unoxidizedmagnetite, porosity and maturation degree. Additionally, the results provided new industrial settings that confirmed this relationship with the reduction of heat energy (10.7\%).

Keywords: grinding; pellet; microstructural phases 


\section{INTRODUÇÃO}

A pelota é o resultado de uma produção industrial que consiste em três etapas: preparação da matéria-prima, formação da pelota verde e tratamento térmico. A cominuição estabelecida na primeira etapa ocorre a partir da moagem, que tem como objetivo assegurar o rendimento da formação de pelotas verdes a partir dos controles da área superficial específica e dimensão requerida dos grãos [1;2]. Na segunda etapa, formação das pelotas verdes, são adicionados os fundentes e aglomerantes, assim como, realizado o controle o diâmetro das pelotas verdes $(<18 \mathrm{~mm}$ a $>8 \mathrm{~mm}$ ). Por último, o tratamento térmico é concebido pelo processo de sinterização das pelotas verdes parametrizado por meio de ciclos térmicos e perfis de temperatura.

Neste trabalho foram realizadas abordagens no âmbito de uma visão bidimensional ao microscópio óptico, uma tridimensional ao microscópio eletrônico e uma cristalográfica ao módulo EBSD. Os resultados obtidos foram relacionados com o processo da moagem e do tratamento térmico a fim de estabelecer as relações que envolvem os controles industriais, produção e consumos de energia elétrica e térmica.

\section{Geometalurgia e a Pelotização}

A interação entre a visão geológica e a minero-metalúrgica tem sido foco das empresas de mineração e usinas de aglomeração. Atualmente, tem-se buscado a caracterização da matéria-prima com o enfoque da ciência dos materiais, o que suporta a tomada de decisão no processo industrial (Lu 1990; Sá et al. 2004; Dwarapudi et al. 2008; Jiang et al. 2008). As propriedades e características determinadas na matéria-prima, bem como das pelotas, tem sido relacionadas ao contexto geológico. Essa interação com uma abordagem que tem seu início na explotação do minério até a obtenção do produto final constitui a ciência denominada de Geometalurgia (Souza Neto et al. 1998; Graça et al. 2015).

\section{Processo de Moagem}

No Complexo de Tubarão, aplica-se um teste de moagem em minérios com base na Lei de Rittinger (1867) a fim de prever a produção e consumo energético [2], que posteriormente foi expresso a partir de um fator $\mathrm{k}$ [3]. Este fator é uma relação de área, unidade de massa e energia consumida, tendo como foco a área superficial específica de $1.900 \mathrm{~cm}^{2} / \mathrm{g}$. Estudos relacionados mostraram que o ganho de área superficial específica depende não só do conteúdo do policristal, mas também da combinação do tipo morfológico contido no material investigado conforme Figura 1. Quanto maior o fator k, menor a energia requerida para obter uma dada área superficial específica [3]

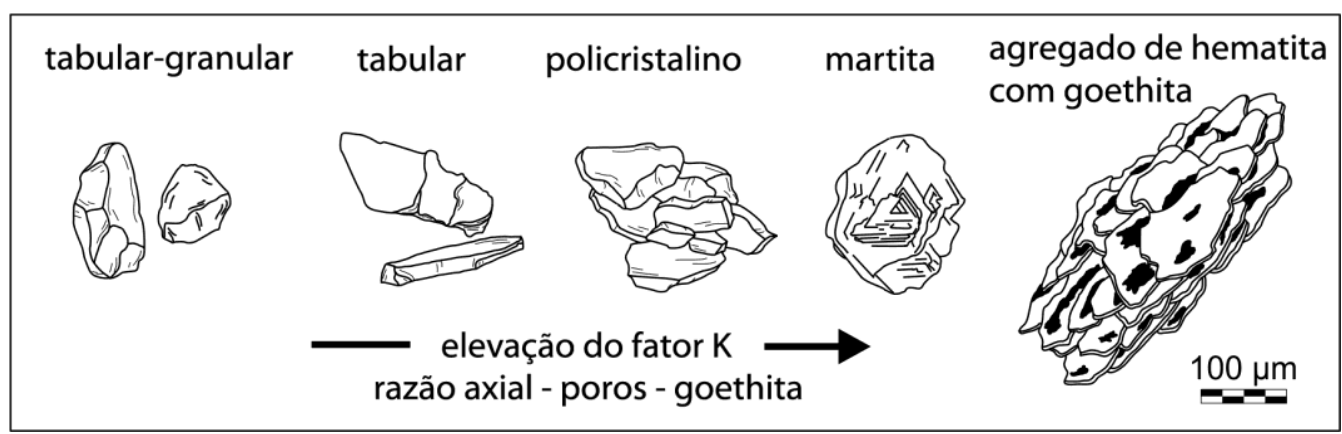


Figura 1. Relação entre os tipos morfológicos e o fator k obtido. Modificado de Graça et al. (2015)

\section{Tratamento Térmico da Hematita e Magnetita}

A hematita representa o estado final de oxidação. O processo de tratamento é determinado basicamente pela coalescência das partículas, que demanda energia para se desenvolver. De outra forma, requer temperatura entre 1.300 e $1.350^{\circ} \mathrm{C}$ e tempos superiores a $20 \mathrm{~min}$. $O$ tratamento térmico da magnetita resulta em transformação de fase por meio de um processo exotérmico. A difusão de oxigênio é acelerada pela temperatura o que resulta na formação de hematita secundária (vide Tabela 1). A particularidade da hematita secundária transcreve um processo diferenciado de ativação da coalescência durante o tratamento térmico, o que resulta em diferentes mecanismos de obtenção da resistência à compressão da pelota [6;7]

\section{Formação de Fases em Pelotas}

Durante o processo de tratamento térmico, a energia aplicada catalisa as reações químicas envolvendo todos os constituintes presentes na pelota. As principais reações químicas encontram-se descritas na Tabela 1.

Tabela 1. Reações químicas em pelotas, temperatura de ignição e os seus resultados

\begin{tabular}{|c|c|c|c|}
\hline reações & $\begin{array}{l}\text { temperatura } \\
\qquad\left({ }^{\circ} \mathrm{C}\right)\end{array}$ & resultados & referências \\
\hline $\begin{array}{l}\mathrm{CaCO}_{3} \rightarrow \mathrm{CaO}+\mathrm{CO}_{2} \\
\mathrm{MgCO}_{3} \rightarrow \mathrm{MgO}+\mathrm{CO}_{2}\end{array}$ & 550 & $\begin{array}{l}\text { óxido de cálcio e } \\
\text { magnésio }\end{array}$ & [4] \\
\hline $\mathrm{CaO}+\mathrm{Fe}_{2} \mathrm{O}_{3} \rightarrow \mathrm{CaO} . \mathrm{Fe}_{2} \mathrm{O}_{3}$ & & cálcio ferrita & \\
\hline $2 \mathrm{CaO}+\mathrm{Fe}_{2} \mathrm{O}_{3} \rightarrow 2 \mathrm{CaO} . \mathrm{Fe}_{2} \mathrm{O}_{3}$ & 450 a 900 & dicálcio ferrita & {$[4 ; 5]$} \\
\hline $\mathrm{MgO}+\mathrm{Fe}_{2} \mathrm{O}_{3} \rightarrow \mathrm{MgO} . \mathrm{Fe}_{2} \mathrm{O}_{3}$ & & magnésioferrito & \\
\hline $\begin{array}{l}2\left(\mathrm{FeO} \mathrm{Fe}_{2} \mathrm{O}_{3}\right)+1 / 2 \mathrm{O}_{2} \rightarrow 3 \mathrm{Fe}_{2} \mathrm{O}_{3}+\mathrm{dQ} \\
(\mathrm{dQ}=260 \mathrm{KJ} / \mathrm{moles})\end{array}$ & 875 a 1.200 & $\begin{array}{l}\text { hematita } \\
\text { secundária }\end{array}$ & {$[6 ; 7]$} \\
\hline \multicolumn{4}{|l|}{$\mathrm{C}_{(\mathrm{s})}+\mathrm{H}_{2} \mathrm{O} \rightarrow \mathrm{H}_{2}+\mathrm{CO}$} \\
\hline \multicolumn{4}{|l|}{$3 \mathrm{Fe}_{2} \mathrm{O}_{3}+\mathrm{CO} \rightarrow 2\left(\mathrm{FeO} \mathrm{Fe}_{2} \mathrm{O}_{3}\right)+\mathrm{CO}_{2}$} \\
\hline $2 \mathrm{MgO}+\mathrm{SiO}_{2} \rightarrow 2 \mathrm{MgO} . \mathrm{SiO}_{2}$ & & magnésio silicato & \\
\hline $2 \mathrm{CaO}+\mathrm{SiO}_{2} \rightarrow 2 \mathrm{CaO} . \mathrm{SiO}_{2}$ & $>1.000$ & dicálcio silicato & \\
\hline $3 \mathrm{SiO}_{2}+2 \mathrm{Fe}_{3} \mathrm{O}_{4}+2 \mathrm{CO} \rightarrow 3\left(2 \mathrm{FeO} . \mathrm{SiO}_{2}\right)+\mathrm{CO}_{2}$ & & fayalita & {$[4 ; 10]$} \\
\hline $\mathrm{MgO}+\mathrm{CaO}+2 \mathrm{SiO}_{2} \rightarrow \mathrm{CaMgSi}_{2} \mathrm{O}_{6}$ & & $\begin{array}{l}\text { cálcio-magnésio } \\
\text { silicato }\end{array}$ & \\
\hline $6 \mathrm{Fe}_{2} \mathrm{O}_{3} \rightarrow 4\left(\mathrm{FeO} \cdot \mathrm{Fe}_{2} \mathrm{O}_{3}\right)+\mathrm{O}_{2}$ & $>1.345$ & magnetita & {$[7 ; 9]$} \\
\hline
\end{tabular}


Para o melhor do conhecimento de alguns autores, o arranjo de fases na microestrutura pode ser relacionado com as propriedades da pelota. A escória formada consiste em ligações térmicas decisivas para o mecanismo de sinterização da pelota que podem gerar alterações nas condições de oxidação da magnetita e de coalescência da hematita $[5 ; 6 ; 7 ; 8 ; 10 ; 11 ; 12 ; 13]$.

\section{OBJETIVOS}

Determinar as principais interações entre características microestruturais e o processos unitários da pelotização. A partir de uma abordagem mais específica, 0 projeto teve duas metas distintas. A primeira, a de associar as variáveis minerais aos resultados dos processos de moagem para capturar desempenho. A segunda, a de entender a formação de fases em pelotas tratadas termicamente e suas relações com os parâmetros deste processo bem como a resistência à compressão do produto final visando capturar ganhos de energia térmica.

\section{MATERIAIS E MÉTODOS}

\section{As amostras e métodos de amostragem e caracterização}

O estudo de caracterização foi realizado para três grupos distintos de amostras: produtos das usinas de concentração - pellet feed (PFXX); pilhas de homogeneização que alimentam a planta industrial (PXXXX); pelotas tratadas termicamente por endurecimento. A composição química dos produtos e pilhas formadas estão estabelecidos na Tabela 2.

Tabela 2. Composição química dos produtos por mina envolvida (conjunto 1) e pilhas formadas (conjunto 2). Pellet feed PFIT, PFBR e PFFN

\begin{tabular}{|c|c|c|c|c|c|c|c|c|c|c|c|}
\hline \multirow{2}{*}{ pilha } & \multirow{2}{*}{$\begin{array}{c}\text { participação } \\
(\%)\end{array}$} & \multirow{2}{*}{$\begin{array}{l}\text { pellet } \\
\text { feed }\end{array}$} & \multicolumn{9}{|c|}{ composição química (\%) } \\
\hline & & & $\mathrm{Fe}$ & $\mathrm{SiO}_{2}$ & $\mathrm{Al}_{2} \mathrm{O}_{3}$ & $\mathrm{P}_{2} \mathrm{O}_{5}$ & $\mathrm{MnO}$ & $\mathrm{CaO}$ & $\mathrm{MgO}$ & $\mathrm{TiO}_{2}$ & PPC \\
\hline \multirow{3}{*}{ P3993 } & 70 & PFBR & 68,48 & 0,58 & 0,53 & 0,02 & 0,02 & 0,01 & 0,01 & 0,08 & 0,82 \\
\hline & 30 & PFFN & 67,11 & 1,09 & 0,48 & 0,06 & 0,13 & 0,01 & 0,04 & 0,05 & 2,08 \\
\hline & \multicolumn{2}{|l|}{ Total } & 67,99 & 0,83 & 0,51 & 0,03 & 0,04 & 0,08 & 0,02 & 0,07 & 1,15 \\
\hline \multirow{3}{*}{ P4023 } & 85 & PFIT & 67,97 & 2,05 & 0,24 & 0,01 & 0,05 & 0,03 & 0,02 & 0,14 & 0,24 \\
\hline & 15 & PFBR & 68,48 & 0,58 & 0,53 & 0,02 & 0,02 & 0,01 & 0,01 & 0,08 & 0,82 \\
\hline & \multicolumn{2}{|l|}{ Total } & 68,59 & 1,06 & 0,26 & 0,01 & 0,03 & 0,03 & 0,03 & 0,12 & 0,37 \\
\hline
\end{tabular}

Os procedimentos de amostragem bem como 0 amostrador foram desenvolvidos conforme os requisitos da norma NBR ISO 3082:2003. A Tabela 3 ilustra a relação entre as amostras utilizadas para a pesquisa e as técnicas aplicadas. 
Tabela 3. Relação entre as amostras estudadas e técnicas aplicadas

\begin{tabular}{|c|c|c|c|}
\hline técnicas aplicadas & pellet feed & $\begin{array}{c}\text { pilhas } \\
\text { homogeneização }\end{array}$ & $\begin{array}{c}\text { pelotas } \\
\text { endurecidas }\end{array}$ \\
\hline peneiramento a úmido & $x$ & $\mathrm{x}$ & \\
\hline permeâmetro Blaine & $\mathrm{x}$ & $\mathrm{x}$ & \\
\hline microscópio ótico (MO) & $x$ & $x$ & $\mathrm{x}$ \\
\hline microscópio eletrônico (MEV) & $x$ & $x$ & \\
\hline EBSD & $x$ & $x$ & $x$ \\
\hline teste de moagem em bancada & $x$ & & \\
\hline teste de moagem industrial & & $\mathrm{x}$ & \\
\hline teste de tratamento térmico (perfil padrão e suave) & & & $\mathrm{x}$ \\
\hline teste de tratamento térmico industrial & & & $x$ \\
\hline ensaio de compressão a frio & & & $x$ \\
\hline
\end{tabular}

\section{RESULTADOS E DISCUSSÃO}

\section{Características Físicas}

Para a série de Tyler, a distribuição granulométrica que melhor representou os produtos pellet feed (PFBR, PFFN e PFIT) assim como as pilhas de homogeneização (P3993 e P4023) foram nas frações [1], [-1 + 0,016], [-0,106 $+0,045]$ e $[-0,045] \mathrm{mm}$, consoante com o estudo desenvolvido por Graça et al. (2015). As características físicas determinadas nas amostras referem-se às percentagens em massa dessas frações, a área superficial específica (SE) e densidade real $\left(D_{R}\right)$ (ver Tabela 4).

Tabela 4. Dados físicos das amostras dos produtos por mina e pilhas formadas

\begin{tabular}{|c|c|c|c|c|c|c|}
\hline \multirow{2}{*}{ amostras } & \multicolumn{4}{|c|}{ distribuição granulométrica (mm) } & \multirow{2}{*}{$\begin{array}{c}\mathrm{SE} \\
{[\mathrm{cm} 2 / \mathrm{g}]}\end{array}$} & \multirow{2}{*}{$\begin{array}{c}D_{R} \\
{[\mathrm{~g} / \mathrm{cm} 3]}\end{array}$} \\
\hline & [1] & {$[-1+0,016]$} & {$[-0,106+0,045]$} & {$[-0,045]$} & & \\
\hline PFBR & $0,09 \%$ & $21,28 \%$ & $46,47 \%$ & $32,15 \%$ & 390,01 & 5,11 \\
\hline PFFN & $0,27 \%$ & $14,55 \%$ & $40,74 \%$ & $44,43 \%$ & 459,03 & 4,95 \\
\hline PFIT & $0,51 \%$ & $14,39 \%$ & $39,12 \%$ & $45,99 \%$ & 409,53 & 5,10 \\
\hline P3993 & $0,12 \%$ & $17,44 \%$ & $44,55 \%$ & $37,89 \%$ & 399,57 & 5,06 \\
\hline P4023 & $0,20 \%$ & $14,26 \%$ & $41,76 \%$ & $43,78 \%$ & 399,44 & 5,14 \\
\hline
\end{tabular}

\section{Características Microestruturais}

\section{Microscópio Eletrônico}

\section{Amostras de Pellet Feed}

O microscópio eletrônico de varredura foi utilizado para observação das características morfológicas nas frações das amostras que apresentaram massa relevante para o estudo.

O pellet feed PFBR é constituído, principalmente, por grãos de hematita tabular. Essa variedade morfológica exibe superfícies planas em cristais delgados de espessura inferior a $20 \mu \mathrm{m}$ e bordas irregulares (Figuras 2) 


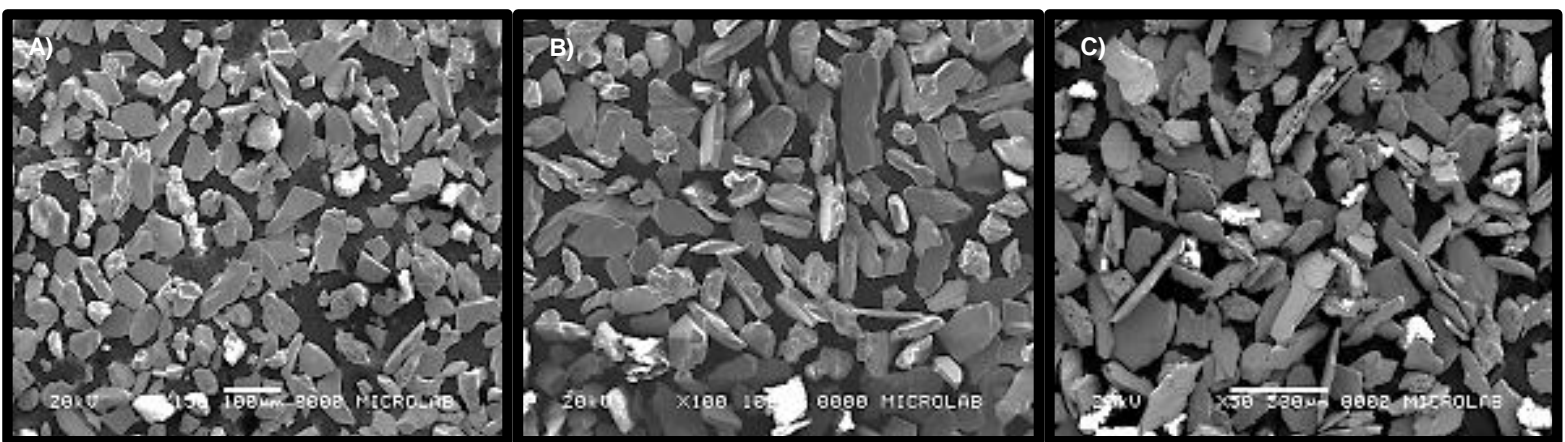

Figura 2. Imagens por elétrons secundários (SEI) que ilustram o pellet feed de PFBR. (A) fração [- 0,045] mm; (B) fração $[-0,106+0,045] \mathrm{mm}$; (C) fração $[-1+0,016] \mathrm{mm}$.

As amostras da mina PFFN são constituídas por grãos de hematita granular, hematita policristalina e tabular. A hematita granular apresenta superfície irregular e seus grãos são equidimensionais. A hematita tabular surge em menor proporção com superfícies planas e espessuras inferiores a $20 \mu \mathrm{m}$. A hematita policristalina é constituída por variedade de grãos com características peculiares contendo seções triangulares similares as da magnetita. Essas evidências de transformação da magnetita para hematita com o hábito preservado da mesma representam a característica principal deste produto (Figura 3).

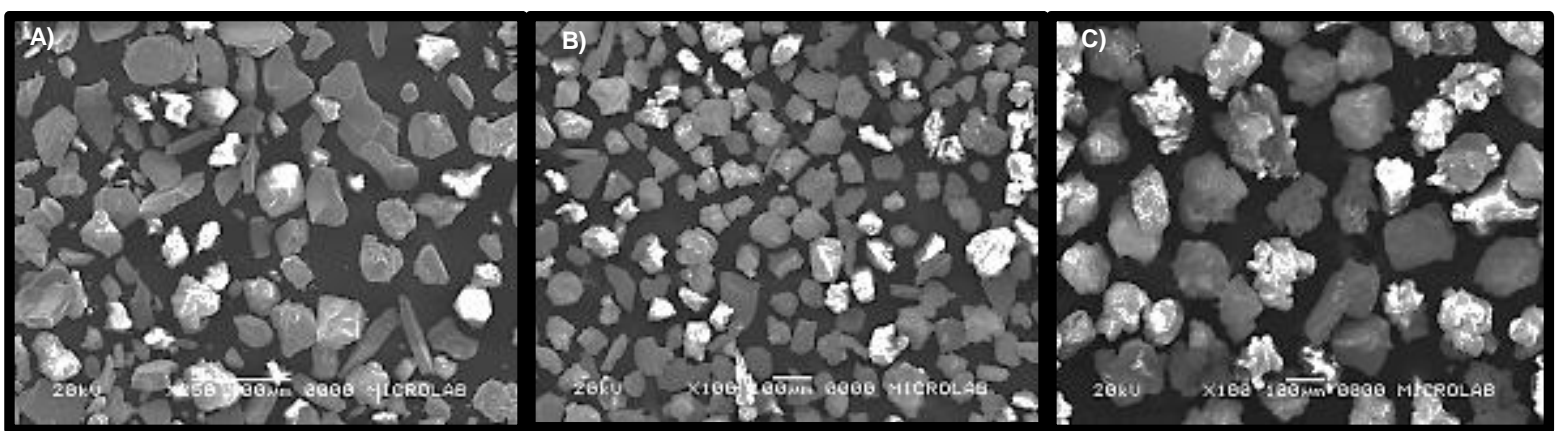

Figura 3. Imagens por elétrons secundários (SEI) que ilustram o pellet feed PFFN. (A) fração [- 0,045] mm; (B) fração $[-0,106+0,045] \mathrm{mm}$; (C) fração $[-1+0,016] \mathrm{mm}$.

O produto PFIT tem o padrão constituído por diversos tipos morfológicos da hematita. Este consiste em agregados de grãos alongados (tabular com espessuras superiores a $20 \mu \mathrm{m}$ ), grãos equidimensionais (granular) e hematita policristalina (Figura 4).

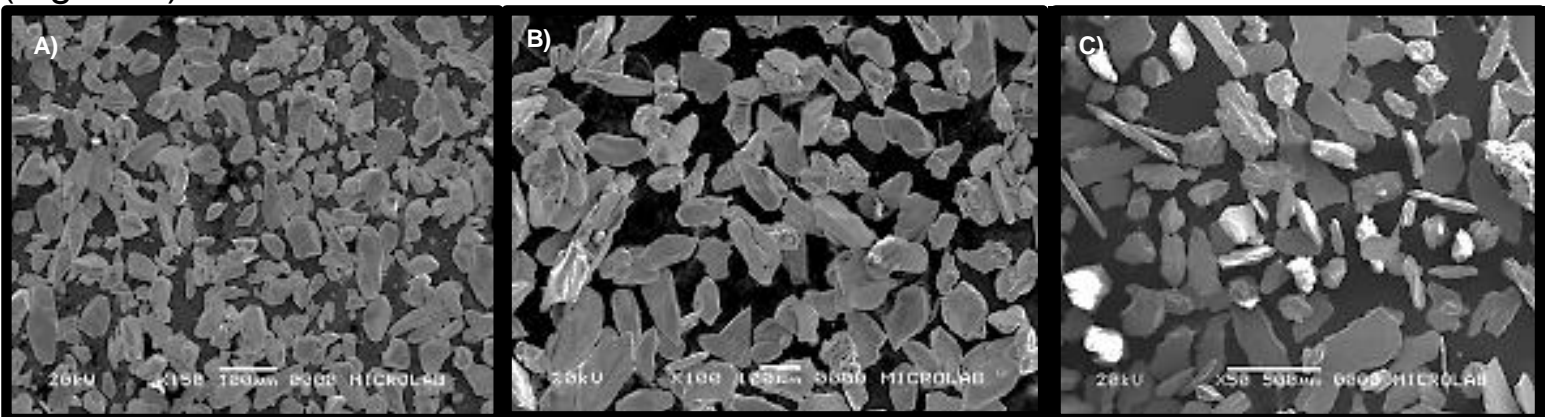

Figura 4. Imagens por elétrons secundários (SEI) que ilustram o pellet feed PFIT. (A) fração [- 0,045] mm; (B) fração $[-0,106+0,045] \mathrm{mm}$; (C) fração $[-1+0,016] \mathrm{mm}$. 


\section{Microscópio Óptico}

\section{Amostras de Pellet Feed, Pilhas de Homogeneização e Misturas Experimentais}

As características mineralógicas foram identificadas em termos de área por fração granulométrica totalizando 500 grãos e policristais por amostra. A Tabela 5 é - resultado global ponderado pelas massas resultantes das quatro frações granulométricas por produto/pilha/mistura selecionadas neste estudo.

Tabela 5. Dados globais da caracterização ao MO para as amostras analisadas

\begin{tabular}{c|ccc|cccc}
\hline \multirow{2}{*}{$\begin{array}{c}\text { características } \\
\text { mineralógicas }\end{array}$} & \multicolumn{3}{|c|}{ produtos (\%) } & \multicolumn{3}{c}{ Pilhas (Pxxxx) / misturas(Mxxx) (\%) } \\
\cline { 2 - 7 } & PFBR & PFFN & PFIT & P3993 & M3993 & P4023 & M4023 \\
\hline Tb & 59,81 & 11,95 & 50,67 & 45,34 & 15,18 & 52,04 & 31,29 \\
Gr & 19,46 & 18,36 & 40,29 & 19,67 & 40,02 & 37,17 & 45,20 \\
HM & 8,18 & 43,64 & 0,74 & 16,69 & 17,82 & 1,86 & 3,12 \\
PGrTb & 2,86 & 0,53 & 4,93 & 4,32 & 0,81 & 4,62 & 0,22 \\
aHG & 0,32 & 0,56 & 0,07 & 0,29 & 0,00 & 0,11 & 0,56 \\
\hline Gth & 8,00 & 24,45 & 1,16 & 13,06 & 17,74 & 2,19 & 2,50 \\
Qz & 0,14 & 0,35 & 1,98 & 0,25 & 1,30 & 1,70 & 4,98 \\
out & 1,23 & 0,16 & 0,16 & 0,38 & 7,13 & 0,32 & 12,13
\end{tabular}

hematita tabular (Tb); hematita granular (Gr); hematita martítica (HM); hematita policristalina (PGrTb); agregado de hematita com goethita (aHG); goethita (Gth); outros (out).

\section{Amostras de Pelotas}

Foram caracterizadas pelotas representativas dos testes de tratamento térmico piloto aplicados nas pelotas verdes geradas a partir das misturas processadas industrialmente (M3993 e M4023). As pelotas representativas foram caracterizadas por mosaico diametral da seção polida. Os poros provenientes do processamento térmico foram quantificados e diagramados. A matriz ferrítica foi caracterizada pela avaliação do grau de maturação e pela quantificação das fases hematita e magnetita. O principal objetivo da caracterização ao MO foi diferenciar a parametrização do processamento térmico das pelotas pela relação perfil de temperatura, formação da microestrutura (fases e poros) e os resultados de resistência à compressão $(\mathrm{RC})$. Para cada modelo de tratamento térmico (perfil de temperatura padrão e suave) foram agrupados os resultados da média de RC das 250 pelotas testadas ( 
Tabela 6).

Tabela 6. Dados da caracterização de pelotas ao MO.

resultados de pelotas ao $\mathrm{MO}$

mistura perfil térmico $\quad \mathrm{RC}$ região da pelota

maturação hematita poros magnetita

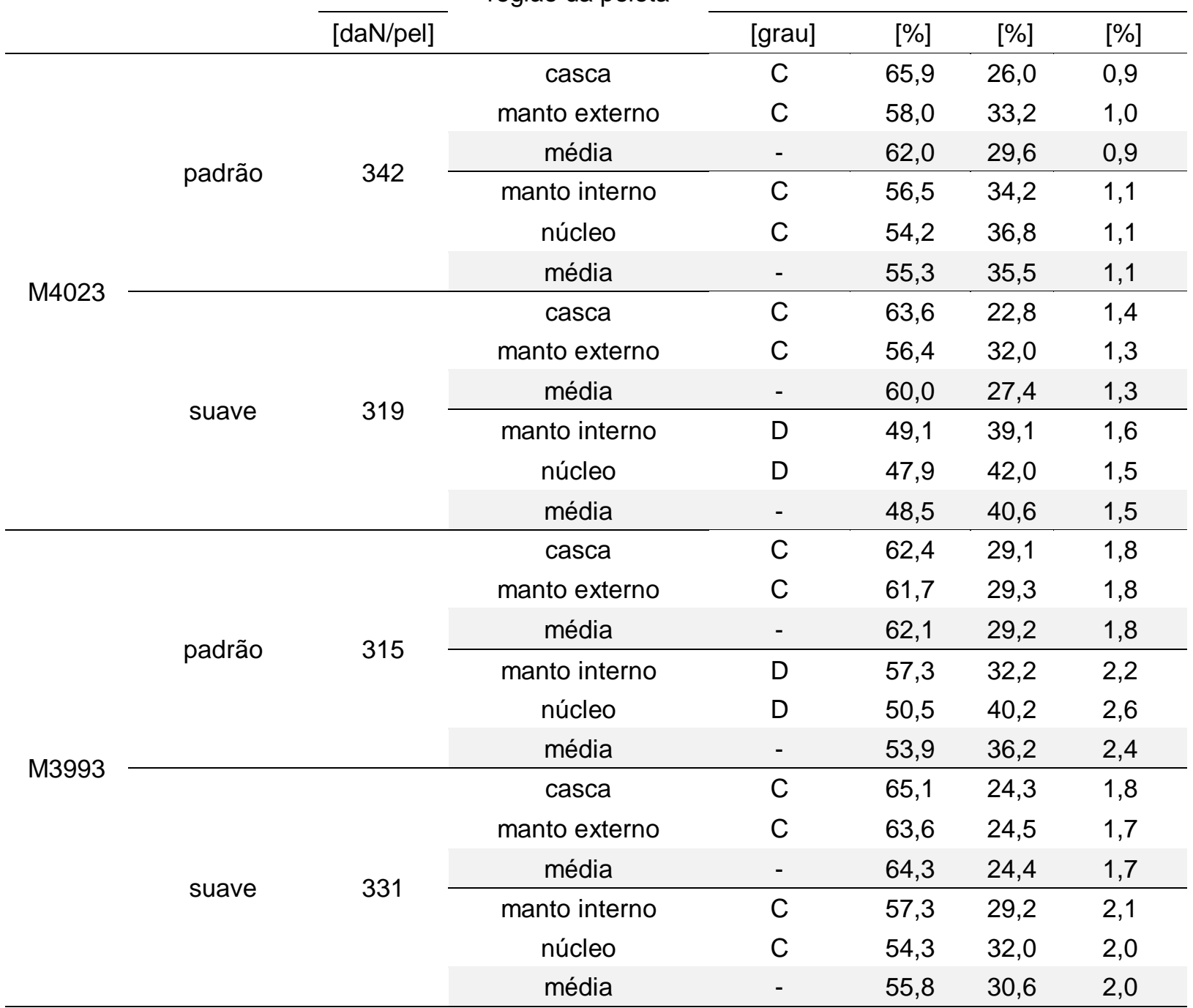

Grau A - baixa coalescência; B: início do processo; C - coalescência completa; D - coalescência intensa

\section{Difração de Elétrons Retroespalhados (EBSD)}




\section{Amostras de Pellet Feed e Pilhas de Homogeneização}

A partir dos mapas de fases foram obtidas as proporções de hematita e magnetita. Os dados apresentados nas Tabelas 7 e 8 foram compilados pela média de quatro regiões analisadas por amostra. A quantidade mínima de pontos foi 500 por região a partir de $4 \mu \mathrm{m}$ de tamanho.

Tabela 7. Dados da relação mineralógica dos produtos das minas envolvidas.

\begin{tabular}{ccccc}
\hline \multirow{2}{*}{ produto } & $\begin{array}{c}\text { fração granulométrica } \\
(\mathrm{mm})\end{array}$ & $\begin{array}{c}\text { participação em massa } \\
(\%)\end{array}$ & \multicolumn{2}{c}{ mineralogia } \\
& {$[-0,045]$} & 32,15 & 30,69 & hematita $(\%)$ \\
magnetita $(\%)$
\end{tabular}

Tabela 8. Dados da relação mineralógica da matéria-prima constituintes das pilhas de homogeneização.

\begin{tabular}{|c|c|c|c|c|}
\hline \multirow{2}{*}{ pilha } & \multirow{2}{*}{$\begin{array}{l}\text { fração granulométrica } \\
(\mathrm{mm})\end{array}$} & \multirow{2}{*}{$\begin{array}{c}\text { participação em massa } \\
(\%)\end{array}$} & \multicolumn{2}{|c|}{ mineralogia } \\
\hline & & & hematita (\%) & magnetita (\%) \\
\hline \multirow{5}{*}{ P3993 } & {$[-0,045]$} & 37,89 & 31,52 & 6,36 \\
\hline & {$[-0,106+0,045]$} & 44,55 & 37,14 & 7,40 \\
\hline & {$[-1+0,016]$} & 17,44 & 15,99 & 1,45 \\
\hline & [1] & 0,12 & 0,11 & 0,01 \\
\hline & \multicolumn{2}{|c|}{ Total } & 84,76 & 15,23 \\
\hline \multirow{5}{*}{ P4023 } & {$[-0,045]$} & 43,78 & 41,52 & 2,26 \\
\hline & {$[-0,106+0,045]$} & 41,76 & 39,98 & 1,78 \\
\hline & {$[-1+0,016]$} & 14,26 & 13,40 & 0,86 \\
\hline & [1] & 0,20 & 0,19 & 0,01 \\
\hline & \multicolumn{2}{|c|}{ Total } & 95,09 & 4,91 \\
\hline
\end{tabular}

\section{Amostras de Pelotas}

A compilação das fases mapeadas ao EBSD serviu como complemento à análise ao MO. Tanto para a amostra M4023 (ver Tabela 11) quanto para a amostra M3993 (ver Tabela 12) os resultados de identificação das fases (hematita e 
magnetita), da porosidade com o comportamento da $\mathrm{RC}$ e perfil de temperatura foram similares ao MO.

Adicionalmente, a técnica EBSD permitiu a identificação de outras nove fases, sendo a fayalita a de maior relevância. A formação dessa fase acompanhou a redução da $\mathrm{RC}$, situação semelhante à reportada pelos autores [4;5;10]. As demais fases identificadas (wustita, quartzo, cálcio-magnésio silicato, dicalcium silicato, SFCA, cálcio ferrita e dicálcio ferrita) não mostraram influencia relevante na $\mathrm{RC}$. 
Tabela 11. Resultados da quantificação de fases para amostras de pelotas relativas ao teste tecnológico de tratamento térmico (mistura M4023)

\begin{tabular}{|c|c|c|c|c|c|c|c|c|c|c|c|c|c|c|c|}
\hline \multirow{3}{*}{ 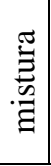 } & \multirow{3}{*}{ 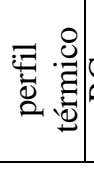 } & \multirow{3}{*}{ 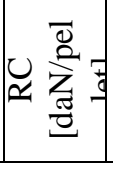 } & \multirow{3}{*}{$\begin{array}{l}\text { região da } \\
\text { pelota }\end{array}$} & \multirow{3}{*}{$\begin{array}{c}\text { poros } \\
(\%)\end{array}$} & \multicolumn{11}{|c|}{ fases minerais $(\%)$} \\
\hline & & & & & \multicolumn{3}{|c|}{ óxido de ferro } & \multicolumn{5}{|c|}{ silicatos } & \multicolumn{3}{|c|}{ ferritos } \\
\hline & & & & & hematita & magnetita & wustita & quartzo & fayalita & $\begin{array}{l}\mathrm{Ca}, \mathrm{Mg} \\
\text { silicato }\end{array}$ & $\begin{array}{l}\text { dicalcium } \\
\text { silicato }\end{array}$ & SFCA & $\begin{array}{l}\text { cálcio } \\
\text { ferrita }\end{array}$ & $\begin{array}{c}\text { dicálcio } \\
\text { ferrita }\end{array}$ & $\begin{array}{c}\text { magnésio- } \\
\text { ferrita }\end{array}$ \\
\hline \multirow{10}{*}{ 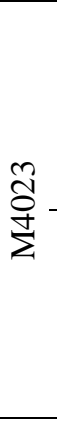 } & \multirow{5}{*}{ 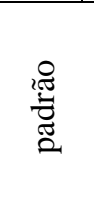 } & \multirow{5}{*}{$\stackrel{\mathscr{F}}{m}$} & casca & 28,46 & 66,72 & 0,45 & 0,08 & 0,34 & 2,61 & 0,43 & 0,02 & 0,04 & 0,17 & 0,27 & 0,41 \\
\hline & & & manto externo & 28,55 & 66,12 & 0,28 & 0,06 & 0,04 & 3,80 & 0,44 & 0,02 & 0,04 & 0,17 & 0,22 & 0,27 \\
\hline & & & manto interno & 22,79 & 73,09 & 0,18 & 0,04 & 0,28 & 2,58 & 0,56 & 0,02 & 0,03 & 0,06 & 0,27 & 0,10 \\
\hline & & & núcleo & 28,00 & 67,61 & 0,13 & 0,06 & 0,01 & 2,99 & 0,27 & 0,02 & 0,06 & 0,25 & 0,52 & 0,08 \\
\hline & & & média & 26,95 & 68,39 & 0,26 & 0,06 & 0,17 & 3,00 & 0,43 & 0,02 & 0,04 & 0,16 & 0,32 & 0,22 \\
\hline & \multirow{5}{*}{$\sum_{\tilde{\omega}}^{ \pm}$} & \multirow{5}{*}{$\stackrel{\ominus}{m}$} & casca & 29,01 & 65,11 & 0,36 & 0,20 & 0,03 & 4,21 & 0,20 & 0,03 & 0,04 & 0,17 & 0,25 & 0,39 \\
\hline & & & manto externo & 30,04 & 62,62 & 1,39 & 0,03 & 0,05 & 3,83 & 0,31 & 0,02 & 0,04 & 0,29 & 0,22 & 1,16 \\
\hline & & & manto interno & 30,00 & 59,51 & 2,87 & 0,05 & 0,32 & 3,55 & 0,49 & 0,03 & 0,04 & 0,22 & 0,24 & 2,68 \\
\hline & & & núcleo & 32,92 & 61,08 & 0,39 & 0,02 & 0,03 & 4,43 & 0,02 & 0,06 & 0,04 & 0,16 & 0,45 & 0,40 \\
\hline & & & média & 30,49 & 62,08 & 1,25 & 0,08 & 0,11 & 4,01 & 0,26 & 0,03 & 0,04 & 0,21 & 0,29 & 1,16 \\
\hline
\end{tabular}

Tabela 12. Resultados da quantificação de fases para amostras de pelotas relativas ao teste tecnológico de tratamento térmico (mistura M3993)

\begin{tabular}{|c|c|c|c|c|c|c|c|c|c|c|c|c|c|c|c|}
\hline \multirow{3}{*}{ 泀 } & \multirow{3}{*}{ 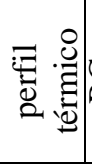 } & \multirow{3}{*}{ 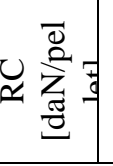 } & \multirow{3}{*}{$\begin{array}{l}\text { região da } \\
\text { pelota }\end{array}$} & \multirow{3}{*}{$\begin{array}{c}\text { poros } \\
(\%)\end{array}$} & \multicolumn{11}{|c|}{ fases minerais $(\%)$} \\
\hline & & & & & \multicolumn{3}{|c|}{ óxido de ferro } & \multicolumn{5}{|c|}{ silicatos } & \multicolumn{3}{|c|}{ ferritos } \\
\hline & & & & & hematita & magnetita & wustita & quartzo & fayalita & $\begin{array}{l}\mathrm{Ca}, \mathrm{Mg} \\
\text { silicato }\end{array}$ & $\begin{array}{l}\text { dicalcium } \\
\text { silicato }\end{array}$ & SFCA & $\begin{array}{l}\text { cálcio } \\
\text { ferrita }\end{array}$ & $\begin{array}{c}\text { dicálcio } \\
\text { ferrita } \\
\end{array}$ & $\begin{array}{l}\text { magnésio- } \\
\text { ferrita }\end{array}$ \\
\hline \multirow{10}{*}{ ूे. } & \multirow{5}{*}{ 承 } & \multirow{5}{*}{$\frac{n}{n}$} & casca & 41,74 & 52,96 & 0,35 & 0,20 & 0,38 & 3,23 & 0,43 & 0,06 & 0,04 & 0,22 & 0,05 & 0,34 \\
\hline & & & manto externo & 30,08 & 62,14 & 0,36 & 0,21 & 1,21 & 4,33 & 0,26 & 0,01 & 0,04 & 0,18 & 0,76 & 0,42 \\
\hline & & & manto interno & 31,90 & 62,55 & 0,50 & 0,20 & 0,13 & 3,53 & 0,38 & 0,04 & 0,04 & 0,25 & 0,12 & 0,36 \\
\hline & & & núcleo & 33,08 & 60,77 & 0,47 & 0,08 & 0,48 & 3,74 & 0,29 & 0,02 & 0,04 & 0,31 & 0,77 & 0,22 \\
\hline & & & média & 34,20 & 59,61 & 0,42 & 0,17 & 0,55 & 3,71 & 0,34 & 0,03 & 0,04 & 0,24 & 0,43 & 0,34 \\
\hline & \multirow{5}{*}{ 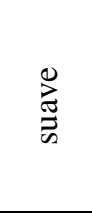 } & \multirow{5}{*}{$\vec{m}$} & casca & 34,78 & 61,10 & 0,20 & 0,11 & 0,04 & 2,72 & 0,27 & 0,02 & 0,04 & 0,20 & 0,33 & 0,19 \\
\hline & & & manto externo & 35,00 & 61,58 & 0,17 & 0,10 & 0,14 & 2,15 & 0,24 & 0,02 & 0,04 & 0,15 & 0,29 & 0,12 \\
\hline & & & manto interno & 26,79 & 68,43 & 0,20 & 0,01 & 0,12 & 2,71 & 0,23 & 0,02 & 0,04 & 0,29 & 0,70 & 0,46 \\
\hline & & & núcleo & 28,20 & 67,24 & 0,30 & 0,00 & 0,03 & 3,54 & 0,17 & 0,01 & 0,04 & 0,10 & 0,07 & 0,30 \\
\hline & & & média & 31,19 & 64,59 & 0,22 & 0,06 & 0,08 & 2,78 & 0,23 & 0,02 & 0,04 & 0,18 & 0,35 & 0,27 \\
\hline
\end{tabular}


A determinação dos teores de fayalita, magnetita não oxidada sugerem uma relação inversa com a resistência à compressão. A geração de uma atmosfera redutora, principalmente no núcleo das pelotas tratadas, por meio do monóxido de carbono proveniente da combustão do antracito introduzido nas misturas e a sílica livre irá fomentar uma fragilidade na estrutura pela formação de magnetita e a fayalita como discutido por Panigraphy et al. (1990) e Dwarapudi et al. (2008). Estas fases relacionadas, embora não presentes em grandes quantidades, podem funcionar como uma rigidez ao stress e ao esforço de carga aplicada à pelota durante transporte e carregamento dos reatores de redução, o que é desejável em certo ponto uma vez que possui interface de ligação entre os grãos de óxido. Mas, ao mesmo tempo, pode atuar como elemento de fragilização que torna o agregado propenso a entrar em colapso após esses processos de manipulação. Isto pode ter um efeito sobre a reatividade das pelotas tratadas termicamente. Materiais frágeis tendem a fraturar facilmente.

\section{Teste de moagem}

\section{Escala em Bancada}

Os produtos testados de cada mina apresentaram uma ordem crescente do fator K: PFFN, seguido PFBR e por último PFIT. A pilha P3993, em função da participação de PFBR e PFFN, apresentou fator $\mathrm{K} 42,4 \%$ superior à pilha $\mathrm{P} 4023$. Os valores do fator $\mathrm{K}$ obtidos por pilha, bem como de cada uma das amostras de produto, estão listados na Tabela 9. A massa passante na malha $[-0,045] \mathrm{mm}$ de cada amostra e área superficial específica (SE) de entrada e saída complementaram a informação.

Tabela 9. Resultados do teste de moagem em bancada

\begin{tabular}{ccc|cc|c}
\hline & \multicolumn{5}{c}{ escala em bancada } \\
\cline { 2 - 6 } amostras & \multicolumn{2}{c}{ entrada } & \multicolumn{2}{c}{ saída } & \multirow{2}{*}{ fator K } \\
& granulometria & SE & granulometria & SE & \\
\cline { 2 - 6 } & {$[-0,045 \mathrm{~mm}]$} & {$\left[\mathrm{cm}^{2} / \mathrm{g}\right]$} & {$[-0,045 \mathrm{~mm}]$} & {$\left[\mathrm{cm}^{2} / \mathrm{g}\right]$} & {$\left[\mathrm{cm}^{2} / \mathrm{g} \cdot \mathrm{Wh}\right]$} \\
\hline PFBR & $32,15 \%$ & 390,01 & $92,70 \%$ & 2.130 & 1,657 \\
PFFN & $44,43 \%$ & 459,03 & $98,10 \%$ & 3.160 & 2,572 \\
PFIT & $45,99 \%$ & 409,53 & $94,25 \%$ & 1.780 & 1,305 \\
\hline P3993 & $37,89 \%$ & 399,57 & $94,48 \%$ & 2.380 & 1,886 \\
P4023 & $43.78 \%$ & 399,44 & $94,24 \%$ & 1.790 & 1,324 \\
\hline
\end{tabular}

\section{Escala Industrial}

As variáveis-resposta granulometria [- 0,045] $\mathrm{mm}$, área superficial específica (SE) e o fator B.S.A. (unidade de área por massa por energia), assim como a produção dos moinhos, foram calculados e registrados na Tabela 10. 
Tabela 10. Resultados das variáveis-resposta do teste de moagem em escala industrial

\begin{tabular}{cccccccc}
\hline \multirow{2}{*}{ pilha } & \multicolumn{7}{c}{ escala industrial } \\
\cline { 2 - 8 } & \multicolumn{2}{c}{ granulometria } & \multicolumn{1}{c}{ SE } & produção & \multicolumn{2}{c}{ índice B.S.A. } \\
\cline { 2 - 8 } P3993 & $74,045 \mathrm{~mm}]$ & $\sigma$ & {$\left[\mathrm{cm}^{2} / \mathrm{g}\right]$} & $\sigma$ & {$[\mathrm{t} / \mathrm{h}]$} & {$[\mathrm{SE} / \mathrm{kWh} / \mathrm{t}]$} & $\sigma$ \\
\hline P4023 & $78,50 \%$ & $(3,7)$ & 1668 & $(60)$ & 340 & 114,22 & $(6,09)$ \\
\hline
\end{tabular}

Exceto a produção, mantido set point fixo (sem variação significativa), a comparação da matriz de experimentos foi realizada mediante aos testes estatísticos das variáveis-reposta granulometria, SE e fator BSA (Tabela 13)

O teste de Kolmolgorov apontou normalidade na distribuição dos dados compilados (P-valor $>0,05)$, portanto as análises de variância (teste $f$ ) e de hipótese (t stundent) foram aplicadas. Foram encontradas evidência, ao nível de significância de $5 \%$, para o teste $f$. O P-valor $>0,05$ aceita a hipótese de nulidade $\left(H_{0}\right)$, ou seja, não há diferença significativa nas variâncias de cada parâmetro. Esta observação está alinhada com os limites do processo industrial, onde a SE é controlada em um intervalo de 1500 a $1700 \mathrm{~cm}^{2} / \mathrm{g}$ e a granulometria entre $75 \%$ a $90 \%<0,045 \mathrm{~mm}$. Já o fator BSA é uma consequência da SE.

Para a comparação das médias, o teste $t$ student apontou diferença estatística significativa para essas três variáveis-resposta. A hipótese de nulidade para este caso foi rejeitada $\left(\mathrm{H}_{0}\right)$ em função do $\mathrm{P}$-Valor $<0,05$.

Tabela 13. Resultados das variáveis-resposta do teste de moagem em escala industrial

\begin{tabular}{|c|c|c|c|c|}
\hline \multirow{3}{*}{ pilha } & \multirow{3}{*}{$\begin{array}{l}\text { variável- } \\
\text { resposta }\end{array}$} & \multicolumn{3}{|c|}{ testes estatísticos } \\
\hline & & normalidade & variância & hipótese \\
\hline & & [Kolmolgorov] & [teste $\mathrm{f}]$ & [teste t stundent] \\
\hline $\begin{array}{l}\text { P3993 } \\
\text { P4023 }\end{array}$ & $\begin{array}{l}\text { granulometria } \\
{[-0.045] \mathrm{mm}}\end{array}$ & $\begin{array}{c}{ }^{*} \text { normal } \\
(P-\text { Valor }>0,150) \\
{ }^{*} \text { normal } \\
(P-\text { Valor } 0,086)\end{array}$ & $\begin{array}{c}\text { P-Valor } 0,147 \\
\text { * variâncias iguais }\end{array}$ & $\begin{array}{c}\text { médias diferentes em } \\
3,22 \text { pontos percentuais } \\
\text { (P-Valor } 0,020)\end{array}$ \\
\hline $\begin{array}{l}\text { P3993 } \\
\text { P4023 }\end{array}$ & SE & $\begin{array}{c}{ }^{*} \text { normal } \\
(P-\text { Valor }>0,150) \\
{ }^{*} \text { normal } \\
(P-\text { Valor } 0,105)\end{array}$ & $\begin{array}{c}\text { P-Valor 0,315 } \\
\text { * variâncias iguais }\end{array}$ & $\begin{array}{c}\text { médias diferentes em } \\
129,242 \mathrm{~cm} 2 / \mathrm{g} \text { (P-Valor } \\
0)\end{array}$ \\
\hline $\begin{array}{l}\text { P3993 } \\
\text { P4023 }\end{array}$ & $\begin{array}{l}\text { fator } \\
\text { BSA }\end{array}$ & $\begin{array}{c}\text { * normal } \\
(P-\text { Valor } 0,919) \\
{ }^{*} \text { normal } \\
(P-\text { Valor } 0,409)\end{array}$ & $\begin{array}{c}\text { teste f: P-Valor } \\
0,272 \\
\text { * variâncias iguais }\end{array}$ & $\begin{array}{c}\text { médias diferentes em } \\
\text { 30,63 SE/kWh/t (P-Valor } \\
0)\end{array}$ \\
\hline
\end{tabular}

Experimentos foram realizados ao longo dos anos até a definição operacional da mistura análoga à amostra 3993. Os resultados de produção e consumo específico de energia elétrica estão descritos na Figura 5. 


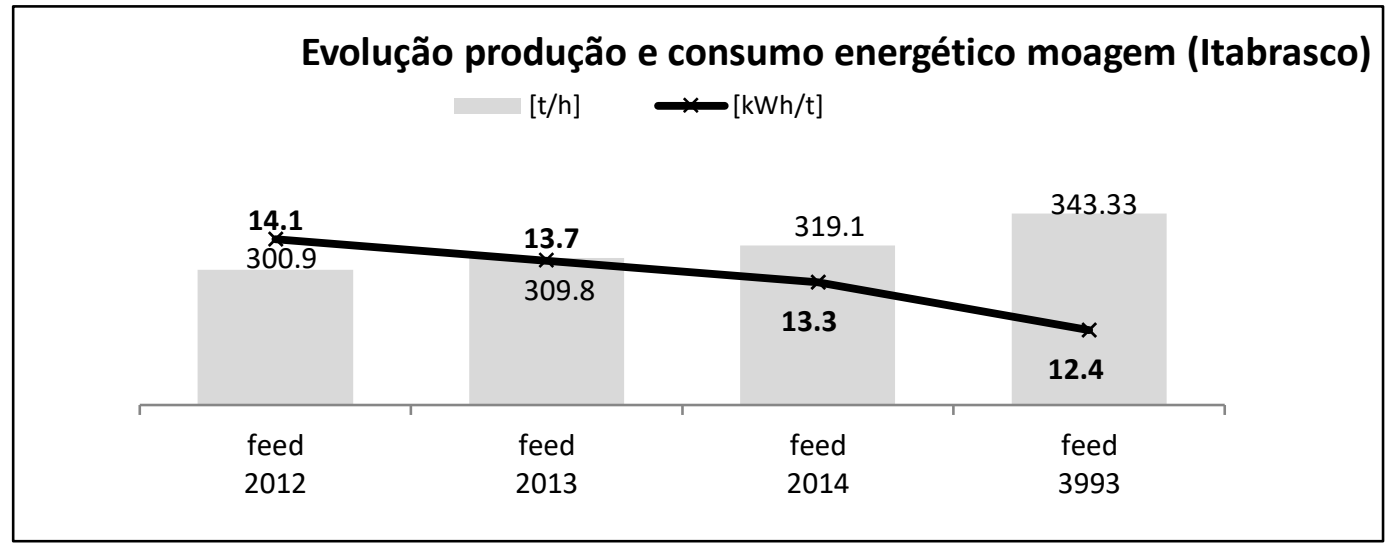

Figura 5. Relação de produção e consumo específico de energia elétrica (base minério moído)

\section{Teste de Tratamento Térmico}

O teste realizado na escala piloto (Pot Grate) foi delineado pela alteração de perfil térmico, um padrão operacional e outro suavizado em relação ao padrão.

\section{Ensaios de Resistência à Compressão}

Os ensaios em 250 pelotas por teste de tratamento térmico estão registrados na

Tabela 14 e as análises estatísticas na Tabela 15.

Tabela 14. Resultados de qualidade física de pelota tratadas termicamente

\begin{tabular}{|c|c|c|c|c|c|c|c|}
\hline \multirow{3}{*}{ mistura } & \multirow{3}{*}{$\begin{array}{c}\text { perfil de } \\
\text { temperatura }\end{array}$} & \multicolumn{6}{|c|}{ qualidade física de pelota } \\
\hline & & $\mathrm{RC}$ & $\sigma$ & $\begin{array}{c}\mathrm{RC} \\
(<250)\end{array}$ & $\begin{array}{c}\mathrm{RC} \\
(<100)\end{array}$ & $\begin{array}{c}\mathrm{RC} \\
(<78)\end{array}$ & abrasão \\
\hline & & [daN/pel] & & [\%] & [\%] & [\%] & [\%] \\
\hline \multirow{2}{*}{ M3993 } & padrão & 315 & (93) & 22,4 & 1,6 & 1,2 & 3,33 \\
\hline & suave & 331 & (88) & 18 & 0,8 & 0,8 & 3,19 \\
\hline \multirow{2}{*}{ M4023 } & padrão & 342 & (118) & 21,2 & 1,6 & 1,2 & 3,61 \\
\hline & suave & 303 & (115) & 30,6 & 3,6 & 2,3 & 4,37 \\
\hline
\end{tabular}

Tabela 15. Resultados das variáveis-resposta do ensaio de resistência a compressão

\begin{tabular}{|c|c|c|c|c|}
\hline \multirow{3}{*}{ mistura } & \multirow{3}{*}{$\begin{array}{l}\text { perfil de } \\
\text { temperatura }\end{array}$} & \multicolumn{3}{|c|}{ testes estatísticos } \\
\hline & & normalidade & variância & hipótese \\
\hline & & [Kolmolgorov] & [teste f ] & [teste t] \\
\hline M3993 & padrão & $\begin{array}{c}{ }^{*} \text { normal } \\
(P-\text { Valor }>0,150) \\
\quad{ }^{*} \text { normal } \\
(P-\text { Valor }>0,150)\end{array}$ & $\begin{array}{c}\text { P-Valor 0,329 } \\
\text { * variâncias iguais }\end{array}$ & $\begin{array}{c}\text { médias diferentes em 16,51 } \\
\text { daN/pel (P-Valor 0,029) }\end{array}$ \\
\hline M4023 & padrão & $\begin{array}{c}{ }^{*} \text { normal } \\
(P-\text { Valor }>0,150)\end{array}$ & $\begin{array}{c}\text { P-Valor } 0,745 \\
\text { * variâncias iguais }\end{array}$ & $\begin{array}{c}\text { médias diferentes em 37,85 } \\
\text { daN/pel (P-Valor 0,001) }\end{array}$ \\
\hline
\end{tabular}


suave

* normal

$(P$-Valor $>0,150)$

Adicionalmente aos resultados de compressão com a identificação de fases, foi evidenciada a relação inversa entre o teor de magnetita na mistura com 0 consumo de energia térmica. $O$ processo de oxidação da magnetita para hematita secundária foi confirmado como a principal variável de parametrização do perfil térmico. Todo este processo pode ser antecipado durante a etapa inicial do tratamento térmico e otimizado ao seu final, assim, a resistência da pelota pode ser obtida demandando menor aporte de energia e consequentemente menor consumo de combustível. O grau de maturação final da pelota também teve seu controle no perfil térmico do forno, pois reflete diretamente a coalescência da matriz ferrítica, que por sua vez, reflete os resultados de resistência à compressão.

\section{Escala Industrial}

A partir dos resultados de compressão apresentados nos testes em escala piloto, experimentos foram realizados com diferentes parâmetros termodinâmicos. Os resultados de consumo específico de energia térmica ao longo dos anos estão descritos na Figura 6.

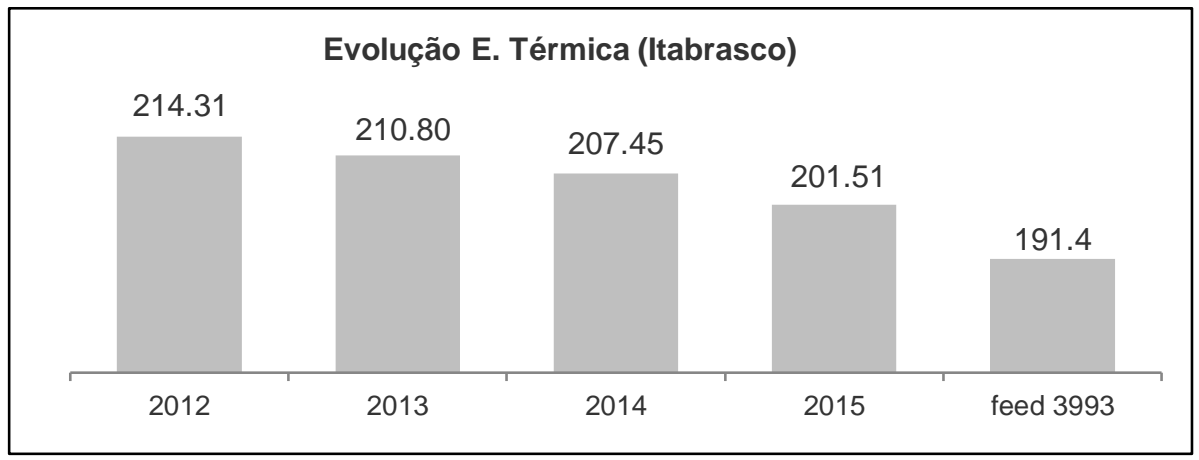

Figura 7. Evolução da energia térmica ao longo dos anos.

\section{CONCLUSÃO}

A combinação de diversas técnicas de microscopia proporcionou uma caracterização detalhada dos produtos das minas envolvidas, assim como da matriz de experimentos tecnológicos aplicados nesta pesquisa, representada pelas pilhas de homogeneização. Os produtos e as pilhas foram caracterizados de acordo com a morfologia e mineralogia do minério, proporcionando uma separação criteriosa por características geométricas e físicas. As técnicas aplicadas via microscópio óptico foram fundamentais para caracterizar a microestrutura das pelotas tratadas termicamente em termos da densidade de poros e identificação das fases hematita e magnetita. Adicionalmente, o desenvolvimento da técnica EBSB permitiu a determinação de outras nove fases cristalinas, além da hematita e magnetita, que estabelece uma forma inédita de observação dessa microestrutura.

Os testes de moagem em bancada confirmaram valores mais elevados de fator k para o produto com presença marcante de hematita martítica, característico do produto de PFFN. Em seguida, a morfologia tabular fina do produto PFBR e finalmente do produto PFIT, onde ocorre a combinação de hematita granular e hematita tabular, sendo essa com espessuras superiores a $20 \mu \mathrm{m}$. Indiferentemente 
das características dos produtos, a pilha composta por uma combinação das morfologias tabular-martítica apresentou valor do fator $\mathrm{k}$ superior à combinação tabular-granular. Em escala industrial, a performance superior da mesma pilha correspondeu aos mais elevados valores do fator industrial BSA, que por sua vez, retratou a relação morfológica das pilhas com ganhos de produção e consumo energético. Em outras palavras, a combinação da porosidade da hematita martítica com a hematita tabular fina proporcionou os melhores resultados industriais.

Por meio dos resultados dos testes de tratamento térmico foi possível estabelecer o controle da resistência à compressão a partir da adequação do perfil térmico no formo, utilizando como base as características mineralógicas que constituem a mistura a ser tratada no processo industrial da pelotização. Os resultados evidenciaram a relação inversa entre o teor de magnetita na mistura com o consumo de energia térmica.

O desenvolvimento da técnica EBSD foi determinante de forma inédita ao identificar outras nove fases cristalinas além da hematita e magnetita. A determinação dos teores de fayalita, magnetita não oxidada também sugerem uma relação inversa com a resistência à compressão.

\section{Referências}

1 Ale S. L. M., Figueira H. V. O. 2002. Tratamento de Minérios. 3a edição - CETEM - Cetro de Tecnologia Mineral, Ministério de Ciência e Tecnologia, CTEC - Coordenação de Inovação Tecnológica. 113 - 120.

2 Mourão J.M., Stegmiller L. 1990. Influência da Estrutura dos Minérios de Ferro na sua Moabilidade. In: Encontro Nacional de Tratamento de Minérios e Hidrometalurgia, 14, Salvador, Anais, 1: 228-243.

3 Graça L. M, Lagoeiro L. E., Lima R. M. F., Barbosa P. F.; Meyer Machado M. 2015. Effect of the Morphological Types in Grinding of Iron-Ore Products. Mineral Processing and Extractive Metallurgy Review: An International Journal, 36:5, 324-331, DOI: 10.1080/08827508.2015.1004405.

4 Meyer K. 1980. Pelletizing of Iron Ores. Wurzburg, Druckerei K. Triltseh.

5 Friel J.J., Erickson E. S. 1979. Microstructure and Reduction Characteristics of Dolomite-Fluxed Magnetite Pellets. Metallurgical Transactions b. volume 1ib, June 1980. P233.

6 Li G.; Jiang T.; Zhang Y.; Tang Z. 2012. Recrystallization of $\mathrm{Fe}_{2} \mathrm{O}_{3}$ During the Induration of Iron Ore Oxidation Pellets. Recritallization, Prof. Krzystof Sztwiertnia (Ed.), ISBN: 978:953:51-0122-2. In Tech.htpp://www.intechopen.com/booksq/recrystallization/recrystallization-of-fe2o3-during-theinduration-of-iron-ore-oxidazed-pellets-

7 Jiang T., Zhang Y., Huang Z. 2008. Preheating and Roasting Characteristics of HematiteMagnetite (H-M) Concentrate Pellets. Iron making Steelmaking, Vol. 35, No. 1, ISSN 0301-9233. 21-26.

8 Dwarapudi S., Devi T. U., Mohan Rao S., Ranjan M. 2008. Influence of Pellet Size on Quality and Microstructure of Iron Ore Pellets. ISIJ International, vol. 48 (2008), No. 6, pp. 768-776.

9 Sá K.G., Costa G.M., Vieira C.V. 2004. Efeito da Composição Mineralógica na Resistência a Compressão de Pelotas de Minério de Ferro. Tecnologia em Metalurgia e Materiais, 1:18-22.

10 Lu W. K. 1990. Fluxed Pellets With High Coke Breeze Addition. Ironmaking Conferece Proceeding. 3-11. 
11 Baker L.A., Thomas C.G., Cornelius R.J., Lynch K.S., Armstrong G.J. 1973. Effect of Goethite on Production Rate in a Traveling Grate Pellet Plant. Society of Mining Engineers, 254:270-278.

12 Panigrahy S.C., Jena B.C., Rigaud M. 1990. Characterization of Bonding and Crystalline Phases in Fluxed Pellets Using Peat Moss and Bentonite as Binders. Metallurgical Transactions b. Volume $21 b,-463$.

13 Scarlett N.V.Y., Madsen I.C., Powncebya M.I., Christensenbin A.N. 2004. Situ X-Ray Diffraction Analysis of Iron ore Sinter Phases. J. Appl. Cryst. (2004). 37, 362-368.

\section{Agradecimentos}

A Vale pelos recursos para realização do estudo, aos professores do Programa de Pós-Graduação, Departamento de Geologia, Escola de Minas (UFOP) e aos colegas da Unidade Técnica e da Usina Piloto da Diretoria de Pelotização. 